Article

\title{
Study of Carbide Dissolution and Austenite Formation during Ultra-Fast Heating in Medium Carbon Chromium Molybdenum Steel
}

\author{
Spyros Papaefthymiou ${ }^{1, *(1)}$, Marianthi Bouzouni ${ }^{1,2}$ and Roumen H. Petrov ${ }^{3,4}$ ([) \\ 1 Laboratory of Physical Metallurgy, Division of Metallurgy and Materials, School of Mining \& Metallurgical \\ Engineering, National Technical University of Athens, 9, Her. Polytechniou str., Zografos, \\ 15780 Athens, Greece; mbouzouni@elkeme.vionet.gr \\ 2 Department of Physical Metallurgy and Forming, Hellenic Research Centre for Metals S.A. -ELKEME S.A., \\ 61st km Athens-Lamia Nat. Road, 32011 Oinofyta, Viotia, Greece \\ 3 Department of Materials Science and Engineering, Delft University of Technology, Mekelweg 2, \\ 2628CD Delft, The Netherlands; Roumen.Petrov@UGent.be \\ 4 Department of Electrical Energy, Metals, Mechanical constructions \& Systems, Ghent University, \\ Technologiepark 903, 9052 Gent, Belgium \\ * Correspondence: spapaef@metal.ntua.gr; Tel.: +30-210-772-4710
}

Received: 24 July 2018; Accepted: 9 August 2018; Published: 16 August 2018

\begin{abstract}
In this study, UltraFast Heat Treatment (UFHT) was applied to a soft annealed medium carbon chromium molybdenum steel. The specimens were rapidly heated and subsequently quenched in a dilatometer. The resulting microstructure consists of chromium-enriched cementite and chromium carbides (in sizes between 5-500 nm) within fine (nano-sized) martensitic and bainitic laths. The dissolution of carbides in austenite $(\gamma)$ during ferrite to austenite phase transformation in conditions of rapid heating were simulated with DICTRA. The results indicate that fine $(5 \mathrm{~nm})$ and coarse $(200 \mathrm{~nm})$ carbides dissolve only partially, even at peak (austenitization) temperature. Alloying elements, especially chromium ( $\mathrm{Cr}$ ), segregate at austenite/carbide interfaces, retarding the dissolution of carbides and subsequently austenite formation. The sluggish movement of the austenite/carbide interface towards austenite during carbide dissolution was attributed to the partitioning of $\mathrm{Cr}$ nearby the interface. Moreover, the undissolved carbides prevent austenite grain growth at peak temperature, resulting in a fine-grained microstructure. Finally, the simulation results suggest that ultrafast heating creates conditions that lead to chemical heterogeneity in austenite and may lead to an extremely refined microstructure consisting of martensite and bainite laths and partially dissolved carbides during quenching.
\end{abstract}

Keywords: Ultra-Fast heating; simulation; dissolution; microstructure; martensite; bainitic ferrite

\section{Introduction}

The kinetics of carbide dissolution during austenitization has been thoroughly studied under isothermal conditions [1-9]. The formation of austenite is a structure sensitive process; therefore, the initial microstructure plays a crucial role in the formed austenite. It is well known that in the presence of a ferritic $(\alpha)$-pearlitic $\left(\alpha-\alpha+\mathrm{Fe}_{3} \mathrm{C}\right)$ initial microstructure, the austenite $(\gamma)$ nucleates at ferrite/cementite interface in pearlite. In case of spheroidal cementite carbides, austenite will first nucleate at the junction between a carbide particle and two ferrite grains. As the pearlite interlamellar spacing $(\lambda)$ decreases, the nucleation and growth rate of austenite increase, leading to an overall increase in the transformation rate. The dissolution of carbides continues by carbon diffusion in austenite until either the carbide is dissolved or the austenite achieves its equilibrium carbon content $[4,5]$. 
Moreover, the growth rate of the austenite nucleus depends on the cementite's dissolution and the carbon (C) diffusion [1,5]; thus, in the presence of undissolved carbides, the austenite grain growth can be suppressed.

The effect of alloying elements such as chromium $(\mathrm{Cr})$ and manganese $(\mathrm{Mn})$ on carbide dissolution and austenite formation have been extensively studied [3,4,6,7,10,11]. Judd and Praxton [4] studied the effect of $0.5 \% \mathrm{Mn}$ on the austenite formation next to cementite by measuring the gradual increase in the volume fraction of the austenite. The results showed that the austenite nucleation rate was delayed by $\mathrm{Mn}$ addition. Inspired by the work of Judd and Paxton, Hillert et al. [5] studied theoretically and experimentally the effect of alloying elements on the dissolution of cementite in various reactions that occur during austenitization. They calculated the $\mathrm{C}$ activity difference in ternary systems and showed that in high alloy steels, the reaction rate is controlled by the diffusion of substitutional elements. Liu and Ägren [6,7] also studied the decomposition of cementite during austenitization at $910{ }^{\circ} \mathrm{C}$ in a Fe-Cr-C system. They observed that the outer layers of cementite is enriched with $\mathrm{Cr}$ during the dissolution process. Enrichment in $\mathrm{Cr}$ leads to a supersaturated cementite, which can then decompose into austenite and $\mathrm{M}_{7} \mathrm{C}_{3}$ carbide. When cementite is enriched in $\mathrm{Mn}$, the austenite growth slows down since Mn prevents the dissolution of cementite [8-10]. The retardation of austenite formation and carbide dissolution became apparent in spheroidized particles. Spherical cementite particles contribute to rapid increase of $C$ content in the matrix and the Mn enrichment retarded the reaction.

The application of ultrafast heating to low alloyed steels is considered a new promising route by which a large variety of refined microstructures and properties can be derived [11-16]. Kaluba et al. [17] were among the first to study the effect of rapid heating on austenite formation. They observed that during rapid heating, lath-shaped austenite was triggered by cementite partial dissolution and $C$ supersaturation at ferrite grain boundaries. Liu and Argen et al. [6,7] observed the precipitation of austenite as Widmanstätten plates in Fe-Cr-C steels due to $\mathrm{Cr}$ enrichment of the cementite outer layer. More recently, austenite growth was studied by Cerda et al. [18-20] under ultrafast heating rates, indicating that local $\mathrm{C}$ concentration is responsible for changes in the mechanism of austenite formation. In addition, De Knijf et al. [21], and Cerda et al., [22] studied the effect of ultrafast heating on recrystallization, showing that nucleation of recrystallized ferrite grains is enhanced by increasing the heating rate and results in refined microstructures. Other studies of Cerda, Papaefthymiou and Petrov et al. [20,23] focus on the effect of heating rates and the phase volume fraction and properties of the micro constituents of the initial microstructure. Even though the effect of rapid heating on phase transformations has been studied, the conditions that favor the simultaneous formation of bainite and martensite during quenching from parent austenite with variable carbon content is not well understood.

The purpose of the present work is to study the mechanisms of the phase transformation associated with the carbide dissolution and austenite formation that take place during ultrafast heating, and to correlate them with the formation of mixed microstructures obtained after subsequent quenching. For this purpose, we use dilatometry to apply rapid thermal cycles, optical, scanning and transmission electron microscopy (OM, SEM, TEM) and Electron Backscattered Diffraction (EBSD) to characterize in depth the ultra-fine microstructures (phases, type and phase morphology) obtained after an ultrafast heat treatment. ThermoCalc ${ }^{\circledR}$ and DICTRA [24] were employed to study the diffusion of alloying elements and the carbide dissolution during ultrafast heating and isothermal holding at peak temperature.

\section{Experimental}

\subsection{Materials and Experiments}

A soft-annealed medium carbon chromium molybdenum steel (CrMo steel) with spheroidized cementite was chosen for the rapid thermal cycling experiments. Table 1 shows the chemical composition of the steel used for this rapid heat treatment. The ultrafast heat treatment was applied in 
DIL805A Bähr dilatometer. The temperature was controlled by a "K-type" thermocouple spot welded to the midsection of each specimen. All samples were heated at $\sim 200{ }^{\circ} \mathrm{C} / \mathrm{s}$ to peak temperature of $950^{\circ} \mathrm{C}$ under vacuum and then quenched with helium gas at a rate of $200{ }^{\circ} \mathrm{C} / \mathrm{s}$ to room temperature. The ultrafast heat treatment included peak austenitization at which the isothermal holding time at the austenitization temperature was maximum $2 \mathrm{~s}$.

Table 1. Chemical analysis of CrMo-steel (in wt.\%).

\begin{tabular}{ccccccc}
\hline C & Mn & Si & P & S & Cr & Mo \\
\hline 0.43 & 1.0 & 0.35 & 0.035 & 0.04 & 1.10 & 0.25 \\
\hline
\end{tabular}

\subsection{Material Characterization}

The microstructure was studied by means of Optical Microscopy (OM), Scanning Electron Microscopy (SEM), Electron Backscattered Diffraction (EBSD) and Transmission Electron microscopy (TEM). The characterization was performed on the rolling plane at the center of the heat-treated sample, where the thermocouple was placed. The metallographic samples were prepared according to the standard procedure by grinding and polishing to $1 \mu \mathrm{m}$ diamond paste. The microstructure was revealed by etching with a solution of $4 \% \mathrm{HNO}_{3}$ in ethanol (Nital $4 \%$ ) for $\sim 10 \mathrm{~s}$ at room temperature. Afterwards, the same sample preparation was repeated and the etching was performed this time with $10 \%$ aqueous sodium metabisulphite tint etching solution. The aim was to reveal the multiphase microstructure and to distinguish the areas of interest (e.g., carbides, retained austenite, bainitic ferrite) for the higher magnification techniques. The etching was performed three times in each sample to ensure that color effects are repeatable and trustworthy. Additionally, micro-structural observations were carried out using a FEI XL40 SFEG-SEM (FEI, Amsterdam, Netherlands) operated at $20 \mathrm{kV}$ equipped with Back Scatter Electron (BSE) detector and an Energy Dispersive Spectroscopy (EDS) detector. The EBSD analysis was performed using a FEI XL40 SFEG-SEM operated at $20 \mathrm{kV}$, beam current corresponding to FEI spot size 3 for aperture $100 \mu \mathrm{m}$ and working distance of $10 \mathrm{~mm}$. The samples were $70^{\circ}$ tilted towards the EBSD detector, and the EBSD patterns were acquired with an EDAX Hikari XP camera operated with EDAX-TSL-OIM-Data Collection version 6 software in a hexagonal scan grid with a step size of $90 \mathrm{~nm}$. The orientation data were post-processed using the following grain definition: Grain boundary misorientation higher than $5^{\circ}$, minimum 4 pixels per grain and a confidence index (CI) larger than 0.1. Finally, TEM measurements were conducted with a high resolution JEOL JEM-2100 (JEOL, Tokyo, Japan), operating at 200 kV, equipped with an Oxford energy-dispersive X-ray spectroscopy (EDS) microanalysis system. The TEM measurements were further analyzed with software Crystallographic Toolbox in order to identify the index patterns [25].

\subsection{Material Modelling}

Thermodynamic and kinetic calculations have been conducted using the TCFE8 database from Thermocalc ${ }^{\circledR}$ software (Version 2018a, Thermo-Calc Software AB, Solna, Sweden) in conjunction with the MOBFE3 database from DICTRA software (Version 2018a, Thermo-Calc Software AB, Solna, Sweden). Using Thermocalc ${ }^{\circledR}$, the phase diagram of the CrMo steel was calculated in order to predict the stable phases expected in equilibrium (Figure 1). Two types of carbides are expected in equilibrium: Cementite and $\mathrm{M}_{7} \mathrm{C}_{3}$ carbide. $\mathrm{M}_{23} \mathrm{C}_{6}$ carbide was not considered to affect the $\alpha$ to $\gamma$ transformation; hence, the results of $\mathrm{M}_{23} \mathrm{C}_{6}$ dissolution were excluded for simplicity. Using DICTRA, the dissolution of carbides, the ferrite to austenite transformation and the chemical gradients across interfaces between carbides and the matrix $(\alpha / \gamma)$ were studied during heating and holding at $950{ }^{\circ} \mathrm{C}$. The chemical composition of the phases was determined with Thermocalc ${ }^{\circledR}$ at equilibrium by taking the volume fractions of the components into consideration. Silicon (Si), due to its minor solubility in carbides is removed from the system, which takes into account the elements Fe, C, Cr, Mn and Mo. The carbides were assumed with spherical shape and initial size was set to $5 \mathrm{~nm}$ and $200 \mathrm{~nm}$, 
respectively, as derived by the TEM observations. Since transformation temperatures shift at higher values by increasing the heating rate [21], results obtained from the dilatometry, such as the exact heating rate $\left(200{ }^{\circ} \mathrm{C} / \mathrm{s}\right)$ and the actual $\mathrm{A}_{1} 200^{\circ} \mathrm{C} / \mathrm{s}$ and $\mathrm{A}_{3} 200^{\circ} \mathrm{C} / \mathrm{s}$ of austenite transformation (810 ${ }^{\circ} \mathrm{C}$ and $900{ }^{\circ} \mathrm{C}$, respectively) as designated in the dilatometry curve in Figure 2, are used as an input in the simulation. At the interfaces of carbides with ferrite or austenite was assumed thermodynamic equilibrium (local equilibrium hypothesis). At $810^{\circ} \mathrm{C}$, the austenite is set to nucleate and grow at the interface of carbides with ferrite. In order to understand the concentration profiles calculated by DICTRA, a schematic representation of them is given in Figure 3. In this figure, $C_{\alpha}$ is the $X$ concentration in $\alpha$ phase, $C_{\alpha / \gamma}$ is the $X$ concentration in $\alpha$ phase as expected by equilibrium, whereas $C_{\gamma / \alpha}$ is the $\mathrm{X}$ concentration in $\gamma$ phase as expected in equilibrium. $C_{\gamma}$ is the current $\mathrm{X}$ content of the $\gamma$ phase.

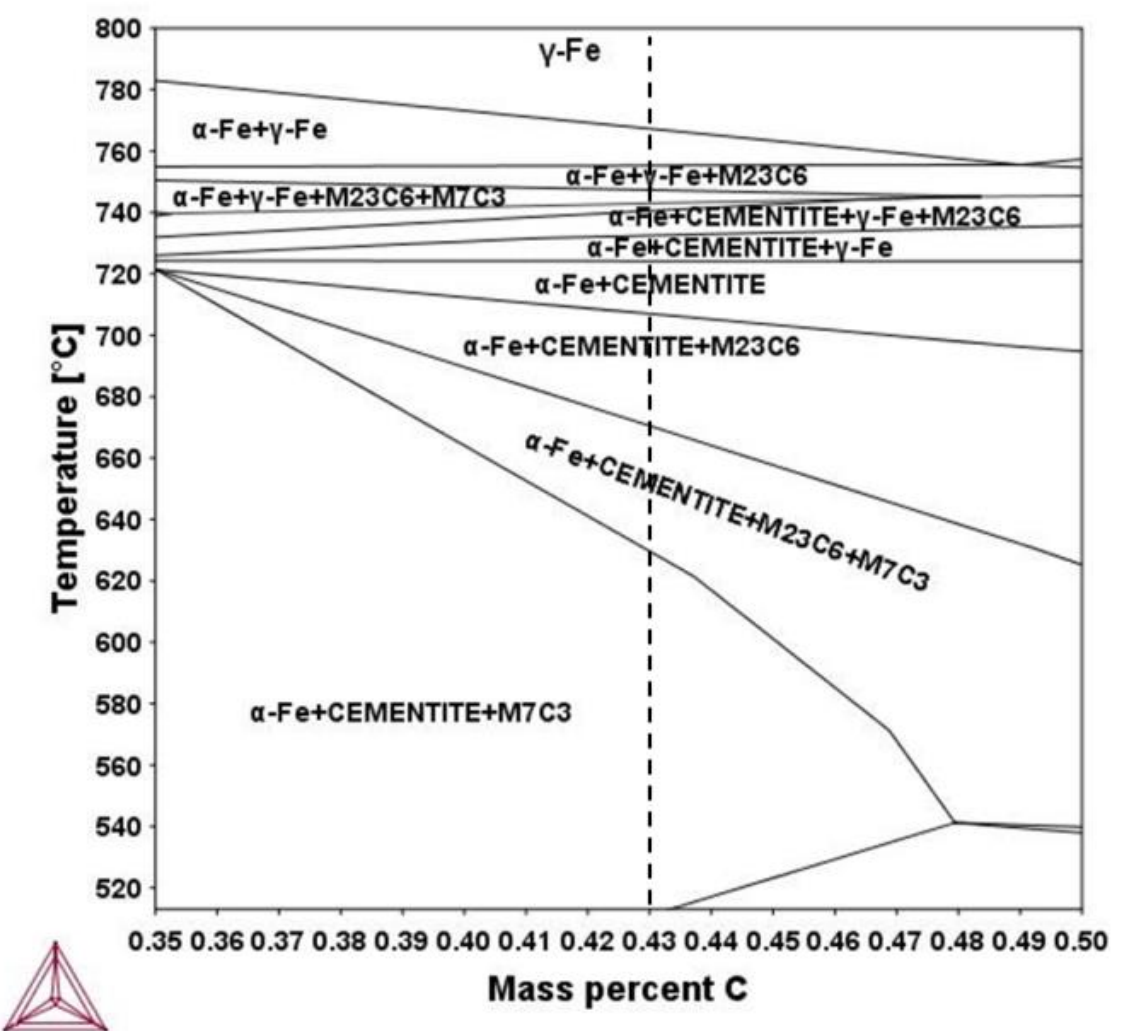

Figure 1. Isopleth of the phase diagram of CrMo steel calculated using Thermocalc ${ }^{\circledR}$ software. The dashed line indicates the carbon $(\mathrm{C})$ content. 


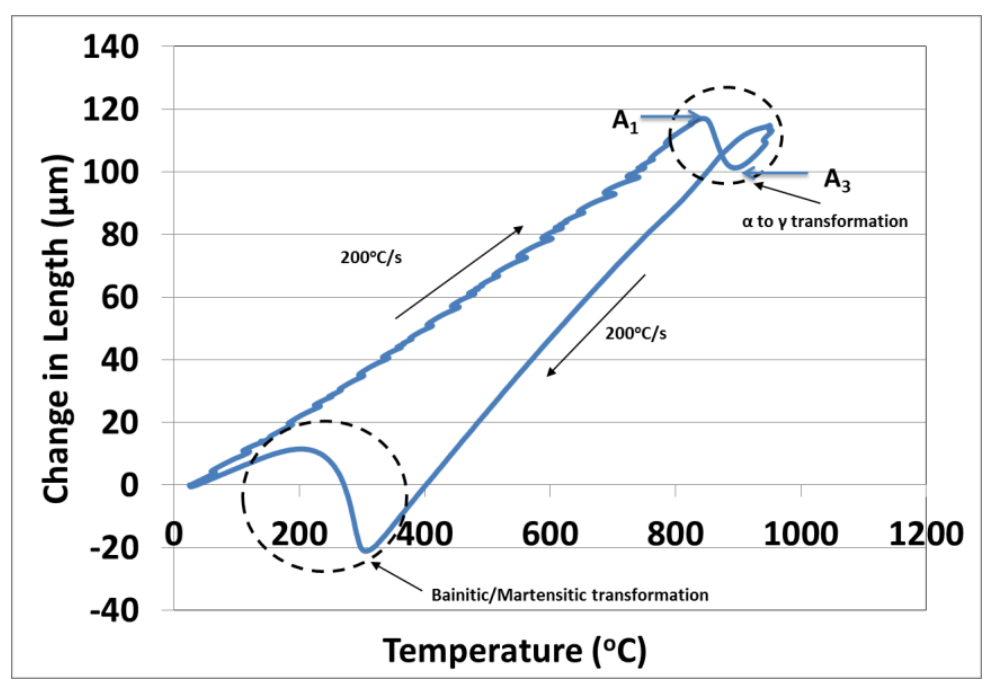

Figure 2. Dilatometry curve of CrMo steel after the UFHT. The change in length at high temperature designates the $\alpha$ to $\gamma$ transformation. The new $\mathrm{A}_{1}$ and $\mathrm{A}_{3}$ temperatures are shifted substantially to $810{ }^{\circ} \mathrm{C}$ and $900{ }^{\circ} \mathrm{C}$, respectively.

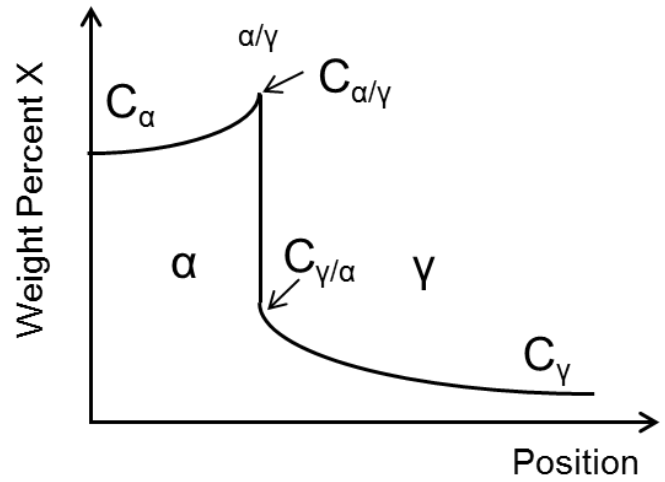

Figure 3. Schematic diagram of the $\mathrm{C}$ concentration profile output of DICTRA.

\section{Results}

\subsection{Microstructure after Ultra-Fast Heat Treatment}

The optical micrograph of the microstructure before and after UFHT is displayed in Figure 4a,b, respectively. The initial microstructure in the soft-annealed condition consists of spheroidized carbides homogeneously dispersed in a ferritic matrix with grain size ranging within 2-10 $\mu \mathrm{m}$ (Figure 4a). The microstructure gained after the UFHT (Figure $4 \mathrm{~b}$ ) is very fine and its constituents cannot be identified clearly on OM, not even at higher magnification. Tint etching has colored areas of the sample differently. According to reference [26], the blue areas indicate possible presence of bainite, while the brown regions indicate martensite laths. In addition, white areas randomly allocated in the microstructure are correlated with carbides or could depict retained austenite.

Figure 5 displays SEM images of the microstructure after the UFHT. The microstructure consists of a mixture of small martensitic/bainitic laths with a size smaller than $5 \mu \mathrm{m}$ and spherical carbide particles. A more detailed analysis on TEM revealed that the laths in the microstructure are nanostructured with width 20-50 nm and 500-1000 nm length. Areas with increased dislocation density (darker areas) were characterized as martensitic laths whereas lighter areas (lower dislocation density) might be an indication of bainitic ferrite laths. The spherical particles were identified as $\mathrm{Cr}$ enriched cementite and $\mathrm{M}_{7} \mathrm{C}_{3}$ type carbide, ranging from $5 \mathrm{~nm}$ to $500 \mathrm{~nm}$. 
Figures 6 and 7 show bright field TEM micrographs of the obtained microstructure after UFHT, indicating the mixed nature of the final microstructure with the coexistence of martensite and bainitic ferrite laths and the different carbides ( $\mathrm{Cr}$ carbide $\mathrm{M}_{7} \mathrm{C}_{3}$ and cementite) of various nano-sizes. The contrast in bright field TEM between laths indicates difference in dislocation density. Darker areas have high dislocation density and thus they are correlated to martensitic laths, whereas lighter areas present lower dislocation density suggesting the formation of bainitic laths (Figure 6a). In addition, laths in which fine elongated cementite have precipitated at the interior with orientation, indicate the appearance of bainitic laths (Figure $6 \mathbf{b}$ ). The diffraction patterns in Figure 8 are taken from the chromium enriched carbide of the type $\mathrm{Cr}_{7} \mathrm{C}_{3}$ (Figure 7a) and the cementite (Figure $7 \mathrm{~b}$ ).

The line scan from the TEM-EDS analysis shown in Figure 9 indicates that significant chemical heterogeneity exists in the microstructure on both sides of a carbide. Table 2 shows the spectra of the points 12, 13, 14, 15 of Figure 9a. These data prove that during the rapid reheating, the microstructure has not had the time to homogenize through diffusion; therefore, the chemical gradients existing at the microstructure prior to UFHT has not been smoothed and exist at the microstructure at peak temperature. Different $C$ concentration and element segregation at the peak temperature serve the setting of different transformation products during the final quench.

The prior austenite grain boundaries (PAGBs) were defined in the microstructure throughout EBSD analysis. The size of the PAGBs is of significance as it influences the microstructural product of the final quench. As an example, too fine austenite restricts the martensite transformation [22,27]. This fact, in combination with the enhanced C content locally, can lead to a restriction of the martensite transformation and an enhancement of the bainitic ferrite or lower bainite transformation during quenching. The EBSD analysis was conducted by assuming the following:

- $\quad \mathrm{K}-\mathrm{S}$ relationship exists between parent austenite and martensite.

- The misorientation associated with martensite boundaries varies from around $10^{\circ}$ to $20^{\circ}, 47-57^{\circ}$ in case of packets and $50^{\circ}-60^{\circ}$ in case of blocks.

- Hence, it can be presumed that misorientations of $20^{\circ}-47^{\circ}$ are due to boundaries corresponding to former austenite grains [28].

Figure 10a shows a normal direction (ND) inverse pole figure map. Based on Figure 10a, it can be seen that similar orientations exist in the same austenite grain. Packets with different orientation are colored differently. Figure 10b shows a gray scale Grain Average Image Quality map on which the different type of boundaries are plotted as follows: Black $-17^{\circ}-47^{\circ}$ (PAGBs), red $-48^{\circ}-55^{\circ}$ probably bainite and blue $-57^{\circ}-65^{\circ}$ martensite. In Figure 9b, the size of PAG (delineated with black lines) were estimated to be less than $10 \mu \mathrm{m}$. Figure 10c depicts the chart of misorientation angle distribution correlated (i.e., only the boundaries between the identified grains are taken into account). The blue line in the chart shows the random distribution of misorientation (MacKenzie type distribution). Different rectangles on the chart show the zone, which are delineated on the grain average image quality map. 

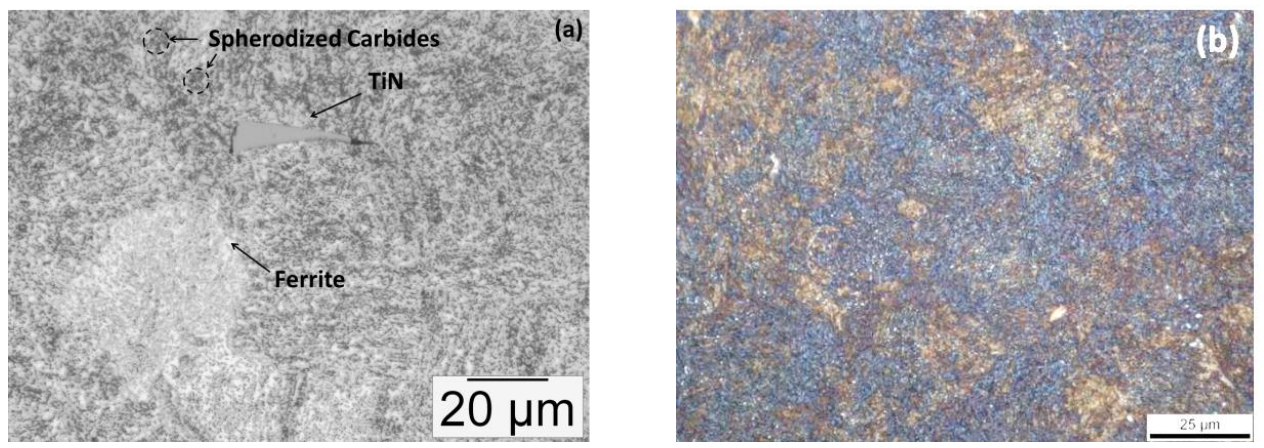

Figure 4. (a) Initial microstructure of the CrMo steel in the soft annealed condition (b) Microstructure of the CrMo steel after UFHT. Blue and brown regions indicate the appearance of bainite and martensite, respectively, while white areas indicate the existence of carbides (or possibly retained austenite).

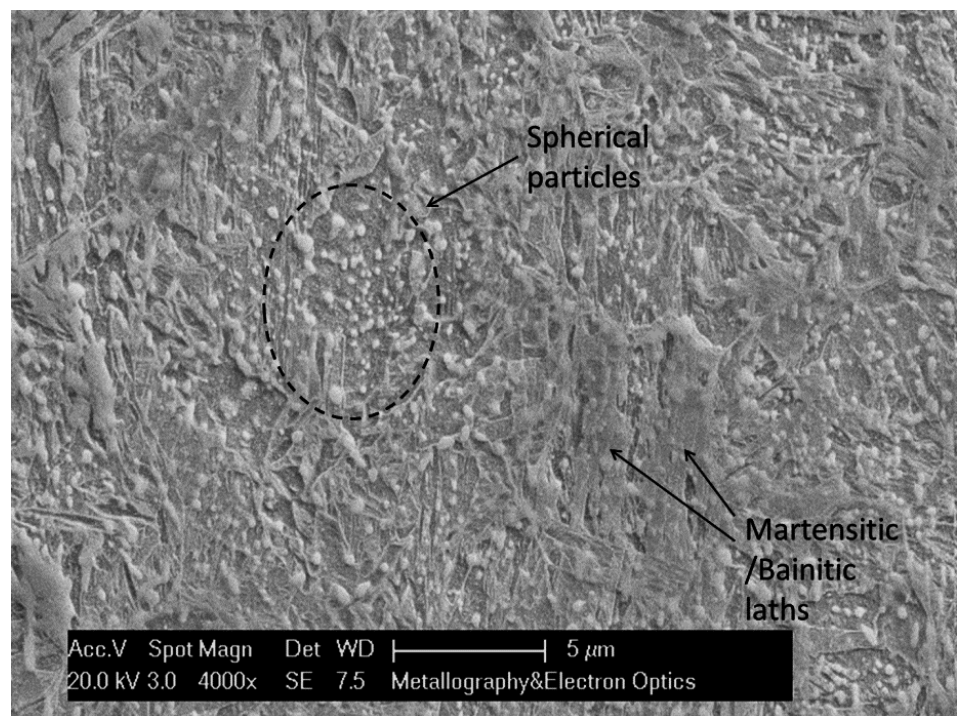

Figure 5. SEM image of the microstructure gained after UFHT. Martensitic/bainitic laths are descernible as well as coarse spherical paricles.
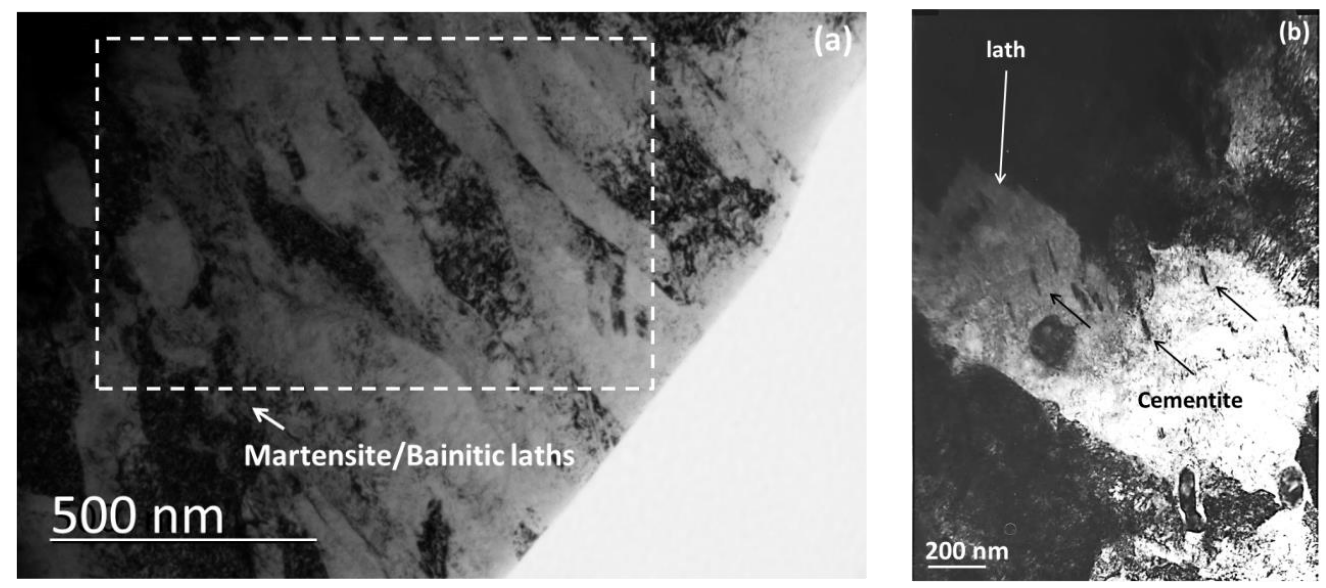

Figure 6. (a) TEM micrograph (bright field) of microstructure after UFHT. Martensite and bainitic ferrite laths have been identified; (b) TEM micrograph (bright field) showing lath in which fine elongated cementite has been precipitated. 

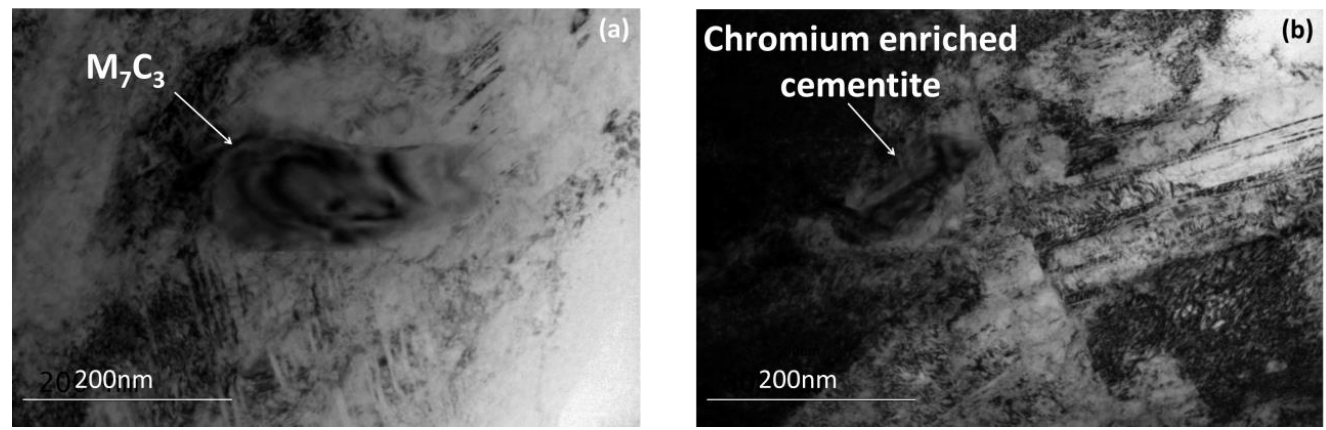

Figure 7. TEM micrograph of microstructure after UFHT (a) Chromium carbide $\mathrm{M}_{7} \mathrm{C}_{3}$ in the microstructure after UFHT; (b) chromium-enriched cementite near grain boundaries.
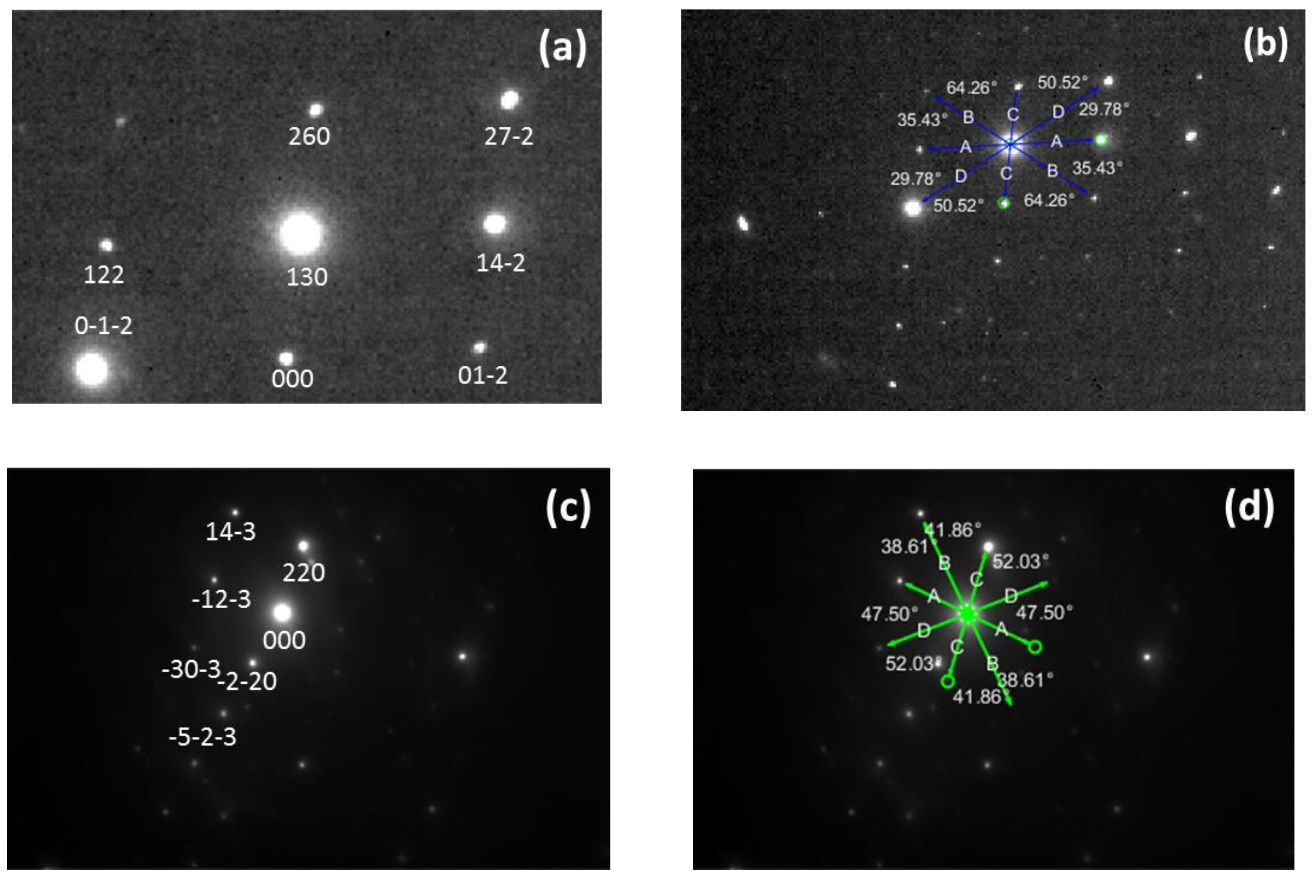

Figure 8. Indexed pattern of Figure 7 (a) chromium carbide of the type $\mathrm{Cr}_{7} \mathrm{C}_{3}$; (b) detected vectors of Cr7C3; (c) chromium-enriched cementite; (d) detected vectors of cementite.

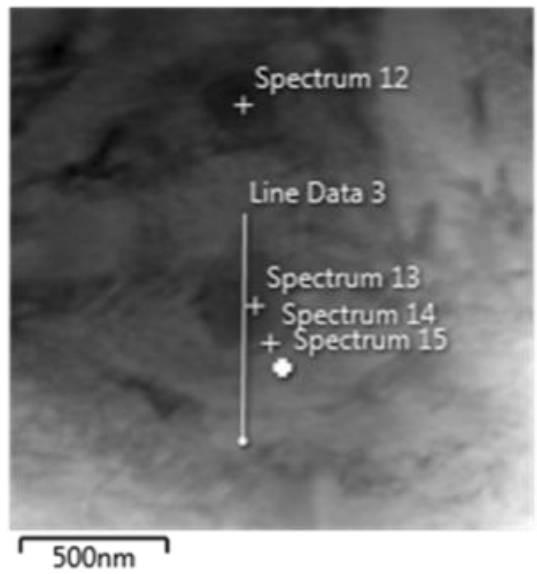

(a)

Figure 9. Cont. 


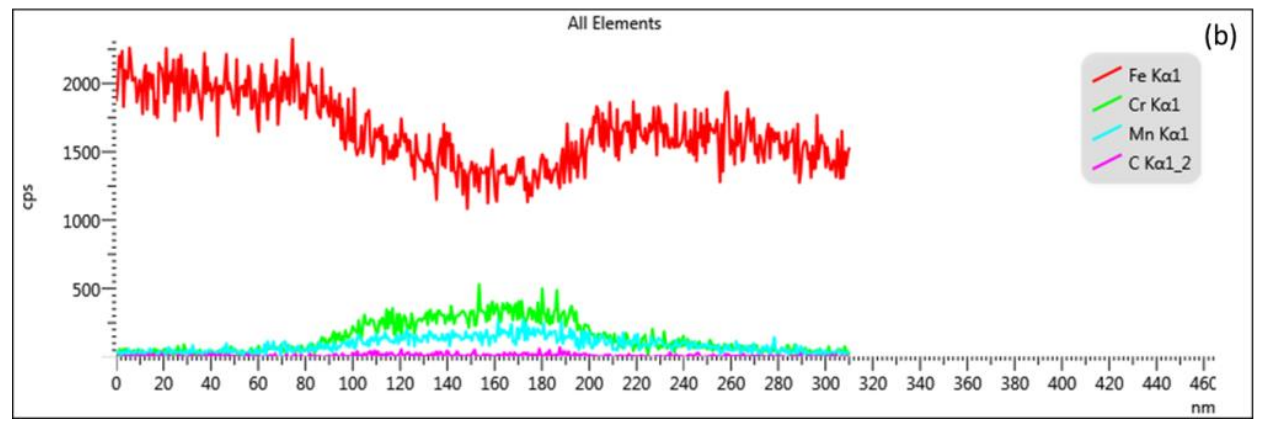

Figure 9. (a) Line scan in the microstructure after UFH; the darker feature corresponds to a carbide; (b) line scan diagram showing chemical heterogeneity.

Table 2. Chemical analysis of spectrums shown in Figure 9a.

\begin{tabular}{ccccc}
\hline Elements & Spectrum 12 & Spectrum 13 & Spectrum 14 & Spectrum 15 \\
\hline $\mathrm{C}$ & 0.38 & 1.27 & - & - \\
$\mathrm{Si}$ & 0.13 & 0.10 & 0.29 & 0.38 \\
$\mathrm{Cr}$ & 10.79 & 14.18 & 3.29 & 0.80 \\
$\mathrm{Mn}$ & 5.85 & 7.66 & 3.06 & 1.15 \\
$\mathrm{Mo}$ & - & 0.38 & - & - \\
$\mathrm{Fe}$ & rest & rest & rest & rest \\
\hline
\end{tabular}
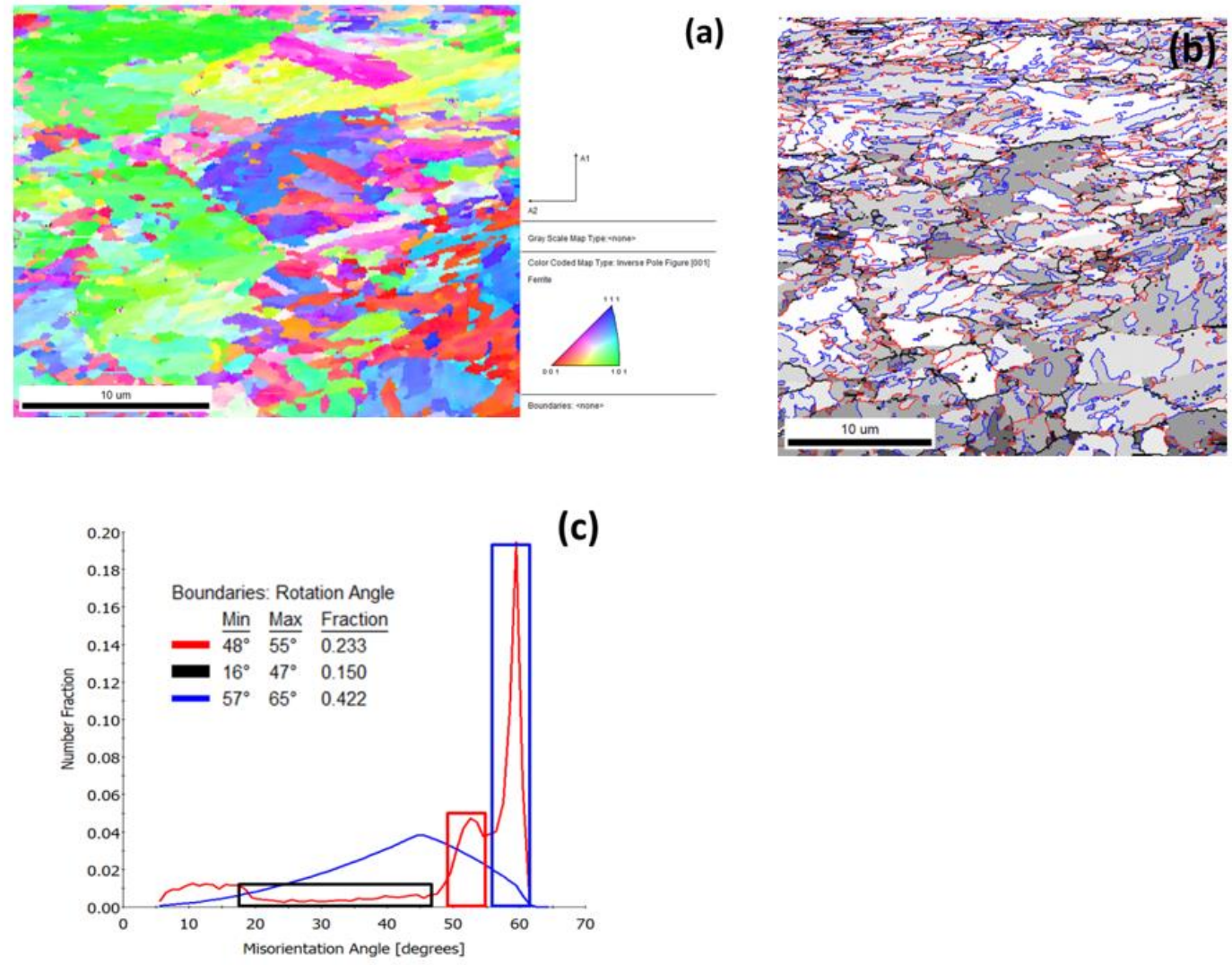

Figure 10. (a) Normal direction (ND) Inverse Pole Figure (IPF) map, (b) Grain Average Image Quality map presenting the different types of boundaries, (c) chart with number fraction distribution of the misorientation angles in the EBSD scan. The colors shown in legend are used to delineate the grain boundaries in Figure 10b. 


\subsection{Modelling results}

The results from DICTRA indicate that even the smaller carbides, e.g., a $5 \mathrm{~nm}$ sized cementite ( $\theta$ ) decrease from $5 \mathrm{~nm}$ to $3 \mathrm{~nm}$. Figures 11-14 show the variation of $\mathrm{Cr}, \mathrm{Mn}, \mathrm{Mo}$ at the $\theta / \gamma$ (cementite/austenite) interface at various critical temperatures for the various sized carbides ( $5 \mathrm{~nm}$ to $200 \mathrm{~nm})$.

Figure 11 shows the variation for $5 \mathrm{~nm}$ sized carbides at the $\theta / \gamma$ interface for $A_{1}, A_{3}$ and $\mathrm{T}_{\text {peak }}$ temperatures.

Figure 12 shows the variation of the $5 \mathrm{~nm}$ sized carbides at the $\mathrm{M}_{7} \mathrm{C}_{3} / \gamma$ (carbide/austenite) interface for $A_{1}, A_{3}$ and $T_{\text {peak }}$ temperatures. The size of the $M_{7} C_{3}$ carbide decreases from $5 \mathrm{~nm}$ to 4.1 nm (Figure 12).

Figure 13 shows the variation for $200 \mathrm{~nm}$ sized carbides at the $\theta / \gamma$ interface for $A_{1}, A_{3}$ and $T_{\text {peak }}$ temperatures. In the case of these larger carbides, cementite slightly decreases from $200 \mathrm{~nm}$ to $195 \mathrm{~nm}$.

Figure 14 shows the variation of the $200 \mathrm{~nm}$ sized carbides at the $\mathrm{M}_{7} \mathrm{C}_{3} / \gamma$ interface for $\mathrm{A}_{1}, \mathrm{~A}_{3}$ and $\mathrm{T}_{\text {peak }}$ temperatures. The $\mathrm{M}_{7} \mathrm{C}_{3}$ carbide seems to be unaffected as it almost does not decrease at all (decreases from $200 \mathrm{~nm}$ to $199 \mathrm{~nm}$, see Figure 14).

As the temperature increases during the UFHT, the substitutional elements $(\mathrm{Cr}, \mathrm{Mn}, \mathrm{Mo})$ tend to accumulate in the vicinity of the carbide interface with austenite. Chromium has the highest spike nearby the interface of carbides with austenite, indicating that there is not enough time for redistribution of $\mathrm{Cr}$.

In fine cementite, the $\mathrm{Cr}$ enrichment in the vicinity of $\theta / \gamma$ interface reaches up to $25 \mathrm{wt} . \%$ (see Figure 11b), while coarse cementite presents a thin spike up to $60 \mathrm{wt.} \%$ (see Figure 12b). The $\mathrm{Cr}$ content close to the $\mathrm{M}_{7} \mathrm{C}_{3} / \gamma$ interface increases up to $60 \mathrm{wt} . \%$ for fine and coarse carbides (see Figures $12 \mathrm{~b}$ and $14 \mathrm{~b}$ ). In case of fine carbides, the slower movement of $\mathrm{M}_{7} \mathrm{C}_{3} / \gamma$ interface compared to the advance of $\mathrm{M}_{3} \mathrm{C} / \gamma$ interface shows that less carbon is in solution in austenite formed nearby $\mathrm{M}_{7} \mathrm{C}_{3}$ than austenite next to cementite. Thus, the austenite that forms next to $\mathrm{M}_{7} \mathrm{C}_{3}$ carbide has lower carbon content ( $\sim .4 \mathrm{wt} . \% \mathrm{C})$ than the austenite that forms next to $\mathrm{Cr}$ enriched cementite particles, which is enriched in carbon $(\sim 1 \mathrm{wt} . \% \mathrm{C})$ at the peak temperature (see Figure 11a and Figure 12a). In the case of coarse carbides, even though the $\theta / \gamma$ interface is advancing further than the interface of $\mathrm{M}_{7} \mathrm{C}_{3} / \gamma$, the austenite formed next to the carbides has a homogeneous carbon distribution of about $0.2 \mathrm{wt} . \% \mathrm{C}$ (see Figures 12a and 13a). Figure 15 summarizes the chemical gradients that exist in the microstructure in austenite, cementite and $\mathrm{M}_{7} \mathrm{C}_{3}$ carbide calculated with DICTRA.
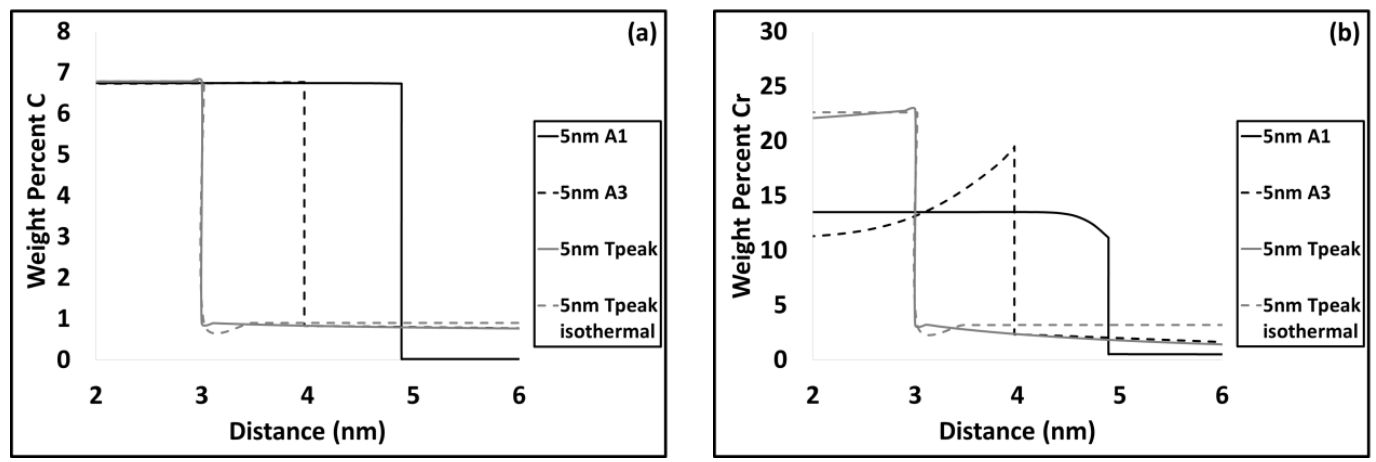

Figure 11. Cont. 

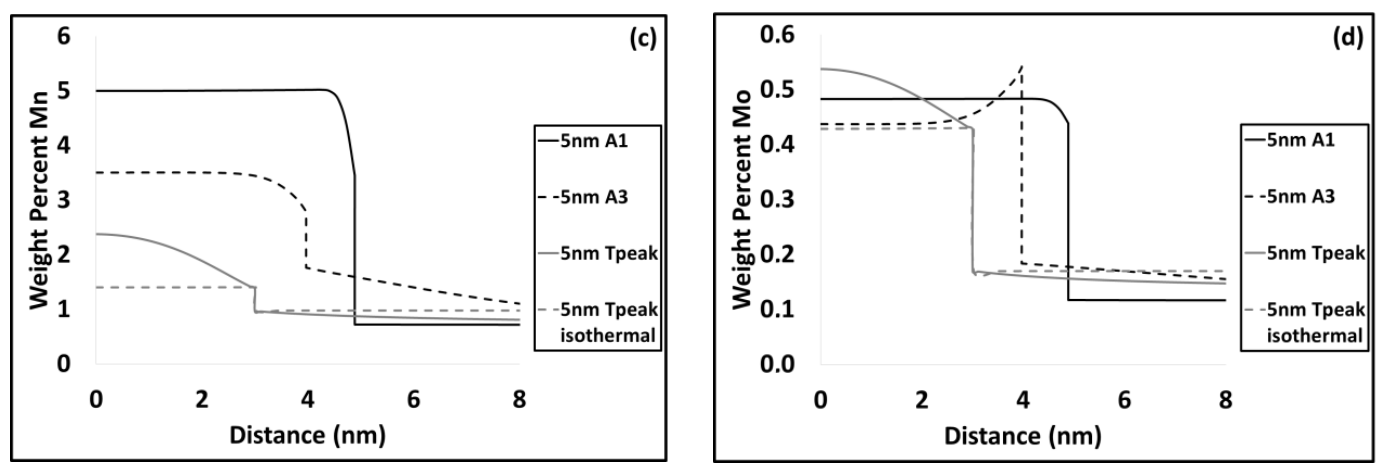

Figure 11. Variation of carbon (a); chromium (b); manganese (c) and molybdenum (d) at the interface of cementite and austenite at various critical temperatures for $5 \mathrm{~nm}$.
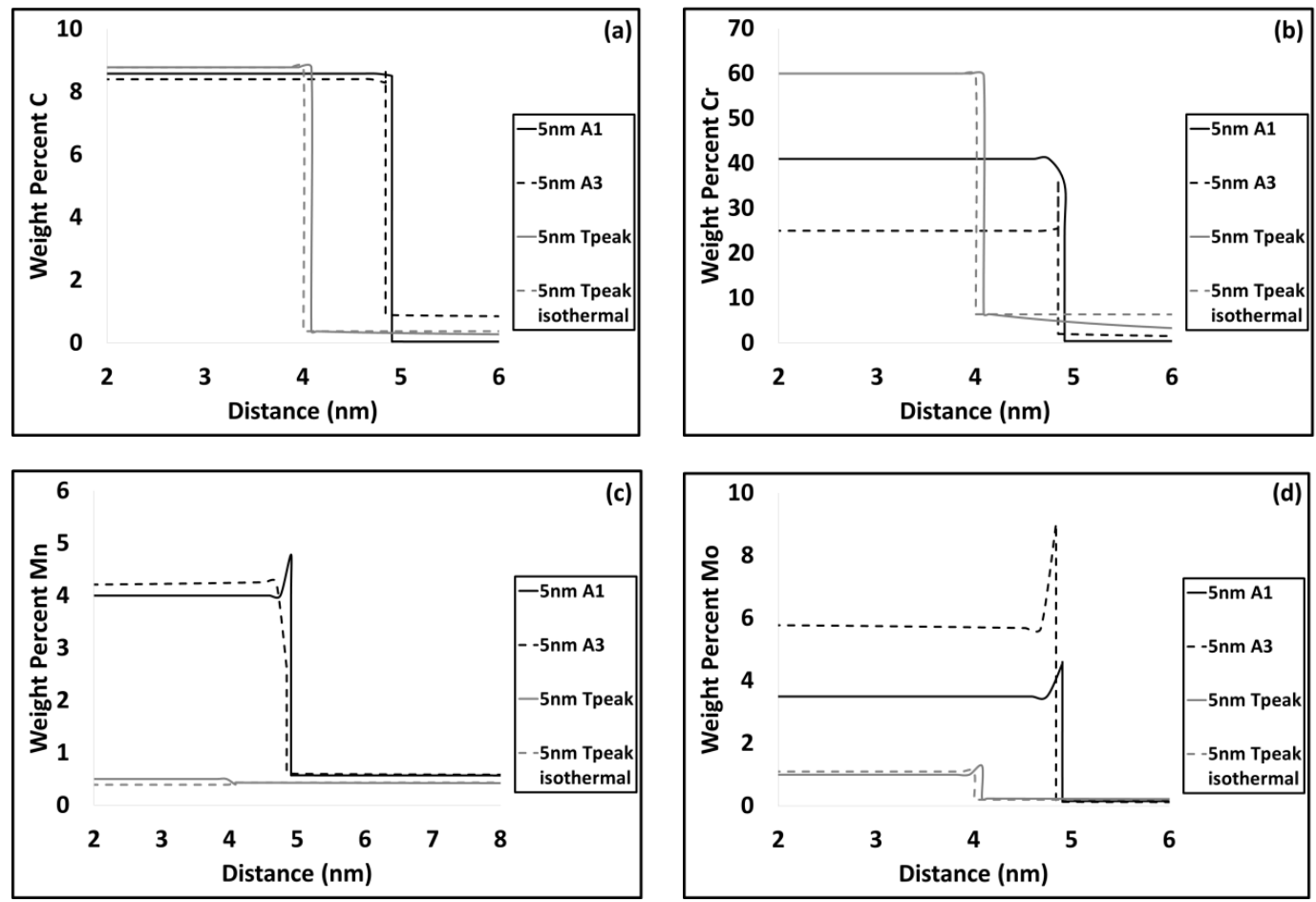

Figure 12. Variation of carbon (a); chromium (b); manganese (c) and molybdenum (d) at the interface of $\mathrm{M}_{7} \mathrm{C}_{3}$ carbide and austenite at various critical temperatures at $5 \mathrm{~nm}$.
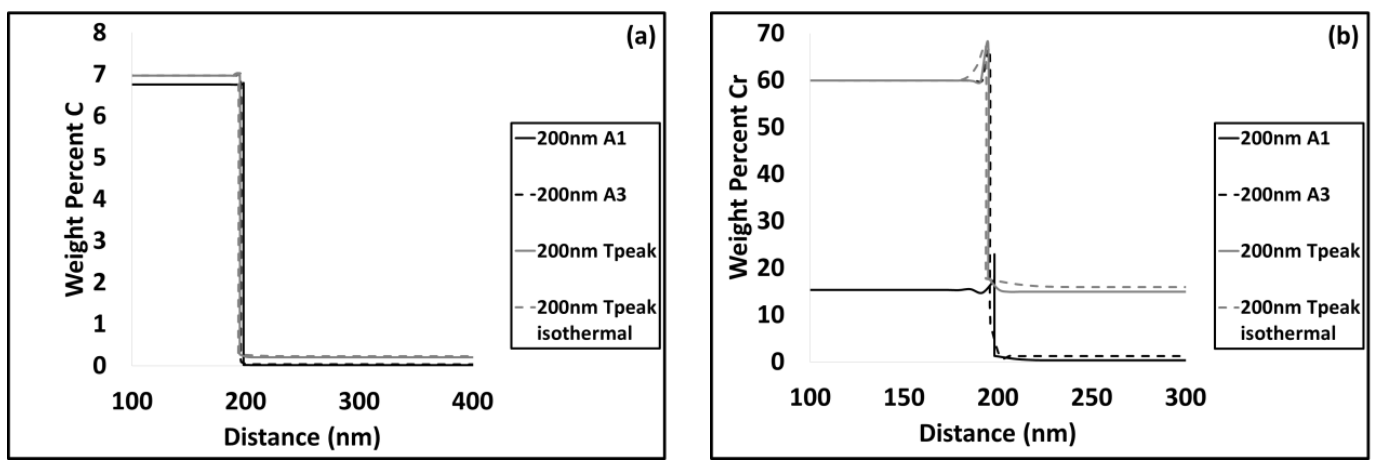

Figure 13. Cont. 

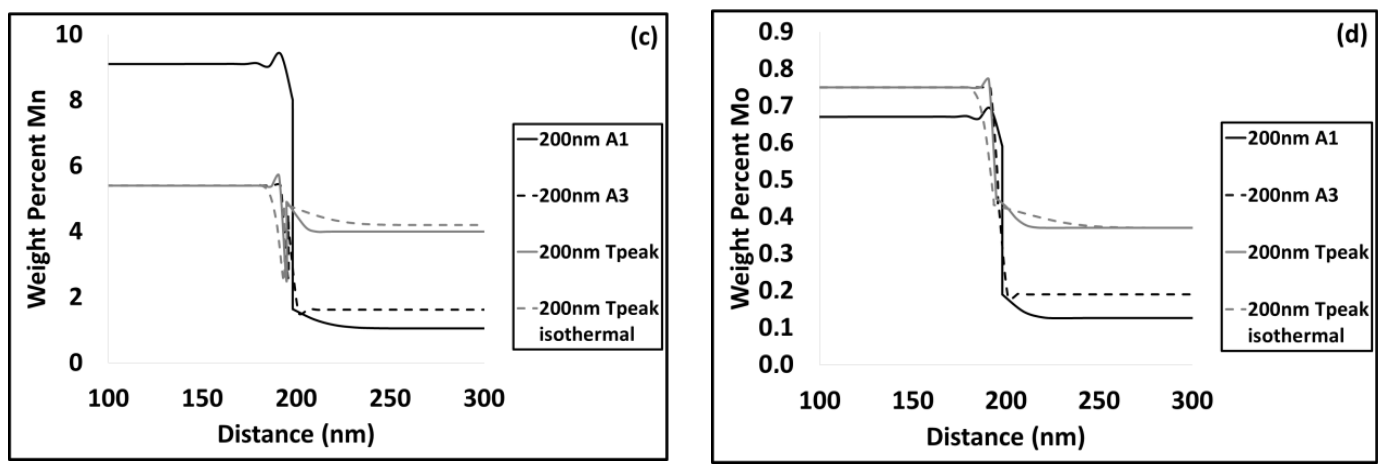

Figure 13. Variation of carbon (a); chromium (b); manganese (c) and molybdenum (d) at the interface of cementite with austenite at various critical temperatures at $200 \mathrm{~nm}$.
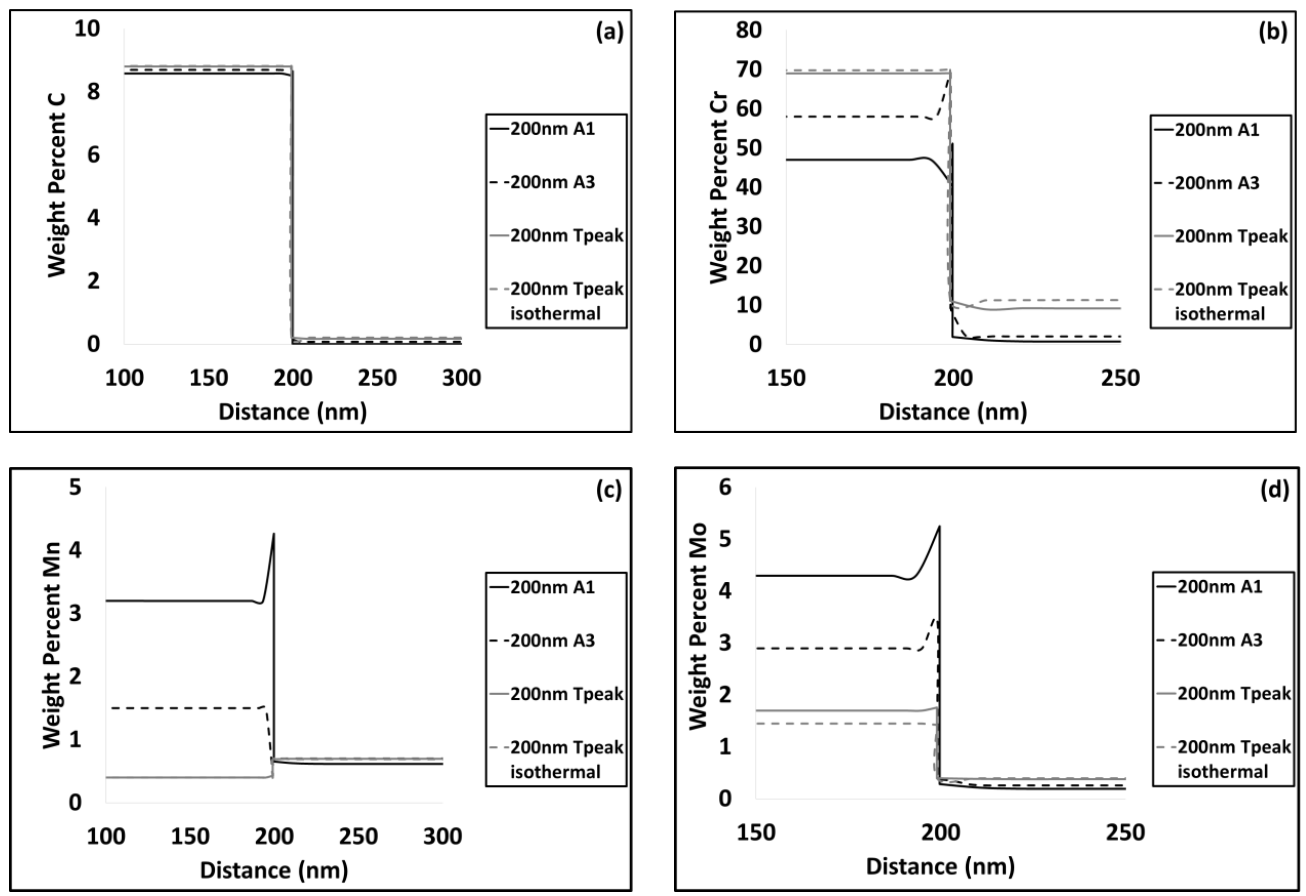

Figure 14. Variation of carbon (a); chromium (b); manganese (c) and molybdenum (d) at the interface of M7C3 carbide and austenite at various critical temperatures at $200 \mathrm{~nm}$.

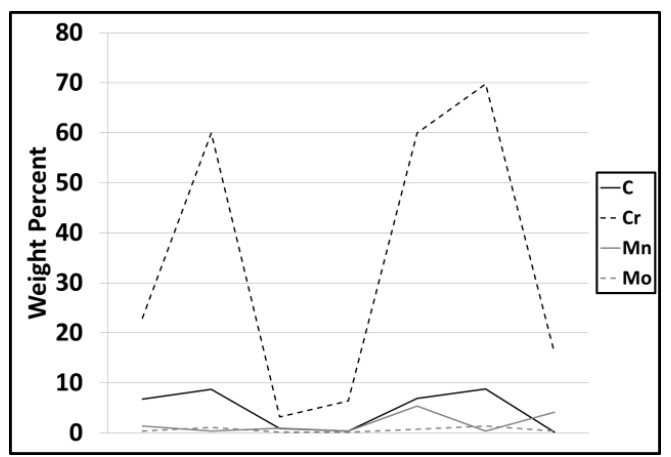

Figure 15. Diagram summarizing the chemical gradients that exist in cementite, $M_{7} C_{3}$ carbide and austenite at $\mathrm{T}_{\text {peak }}$. 


\section{Discussion}

\subsection{Carbide Dissolution}

The difference in dissolution of carbides has been studied in terms of interface velocity and carbon diffusion distance. By taking both the flux balance equation and the flux of carbon for each phase into consideration, the velocity of austenite moving into cementite can be expressed as:

$$
v_{\theta / \gamma}=\frac{D_{k}\left(x_{k}^{\gamma / \theta}-x_{k}^{\gamma / \alpha}\right)}{z\left(x_{k}^{\gamma}-x_{k}^{\theta}\right)}
$$

where $x_{k}{ }^{i / a}$ is the mole fraction of element $k$ of phase $\mathrm{i}$ at the interface $\mathrm{i} / \mathrm{a}, D_{k}$ the diffusion coefficient $\left(\mathrm{m}^{2} / \mathrm{s}\right)$ of element $k$ and $z$ the effective diffusion distance in carbides.

Equation (1) indicates that the effective diffusion distance $z$ is inversely related to the velocity of the carbide/austenite interface, meaning that the atoms (substitutional and interstitial) have greater distance to cover at limited time during the UFHT. The values of interface velocity were estimated numerically in Table 3, which shows the maximum velocity of carbides/austenite obtained with DICTRA.

Table 3. Velocity of $\theta / \gamma$ and $\mathrm{M}_{7} \mathrm{C}_{3} / \gamma$ for fine $(5 \mathrm{~nm})$ and coarse $(200 \mathrm{~nm}$ ) carbides at the beginning of austenite nucleation.

\begin{tabular}{ccc}
\hline Carbide Size & $V_{\Theta / \gamma}(\mathrm{m} / \mathbf{s})$ & $V_{\mathbf{M}_{7} \mathrm{C}_{3} / \gamma}(\mathrm{m} / \mathbf{s})$ \\
\hline $5 \mathrm{~nm}$ & $2.61 \times 10^{-6}$ & $3 \times 10^{-6}$ \\
$200 \mathrm{~nm}$ & $2.5 \times 10^{-6}$ & $1.64 \times 10^{-9}$ \\
\hline
\end{tabular}

To show the difference in the distance for carbon diffusion between equilibrium (normal slow heating) and ultrafast heating, the calculation of the distance for carbon diffusion in austenite was conducted using the known equation of Fick's second law:

$$
\frac{X_{x}-X_{o}}{X_{s}-X_{o}}=1-\operatorname{erf}\left(\frac{z}{2 \sqrt{D t}}\right)
$$

where $X x$ is concentration (mole fraction) at depth $z(\mathrm{~m})$ after time $t(\mathrm{~s}), X o$ is initial concentration (mole fraction), $X s$ is concentration at the surface (mole fraction), and $D$ is diffusion coefficient depending on the temperature $\left(\mathrm{m}^{2} / \mathrm{s}\right)$.

The initial carbon content for the calculation was obtained from DICTRA.

Table 4 shows the diffusion distance for $\mathrm{C}$ at $950{ }^{\circ} \mathrm{C}$ for cementite and $\mathrm{M}_{7} \mathrm{C}_{3}$ carbide for fine and coarse carbides. The results show that the calculated $\mathrm{C}$ diffusion distance is significantly increased in comparison to the carbide interface movement, indicating that there was not enough time for diffusion and the carbide dissolution is controlled by the interface movement and not $C$ diffusion. Therefore, carbides are largely unaffected by the heat treatment.

Table 4. Diffusion distance for carbon at $950{ }^{\circ} \mathrm{C}$ for cementite $(\theta)$ and $\mathrm{M}_{7} \mathrm{C}_{3}$ carbide for fine and coarse carbides.

\begin{tabular}{ccl}
\hline Carbide Size & $\theta / \gamma$ & $\mathbf{M}_{7} \mathbf{C}_{3} / \gamma$ \\
\hline $5 \mathrm{~nm}$ & $13.7 \mathrm{~nm}$ & $0.22 \mu \mathrm{m}$ \\
$200 \mathrm{~nm}$ & $1.41 \mu \mathrm{m}$ & $1.63 \mu \mathrm{m}$ \\
\hline
\end{tabular}

Subsequently, the interface movement is mainly controlled by the diffusion of substitutional alloying element (Cr, Mn, Mo). In order to maintain the local equilibrium at the interface, $\mathrm{Mn}, \mathrm{Cr}$ and 
Mo have to be redistributed between carbides and austenite. As carbides dissolve, $\mathrm{Cr}, \mathrm{Mn}$ and Mo are transferred from carbides to austenite. At the same time, substitutional atoms are transferred from austenite to carbides. Hence, the enrichment in substitutional atoms in the outer layer of austenite stabilizes the carbides. Furthermore, a considerable amount of $\mathrm{Cr}$, Mn and Mo is redistributed inside austenite, increasing its content. From the substitutional atoms, $\mathrm{Cr}$ affects the interface movement the most. Chromium has strong affinity with carbon and tends to co-segregate with it at carbide/austenite interfaces, leading to a solute drag phenomenon. This solute drag impedes the boundary migration. Additionally, Mo and Mn are also carbide-forming elements that also create a solute drag effect. Thus, they further impede interface movement. Moreover, the increased Mn content forms compounds with Fe, which enhances the stability of carbides [29].

\subsection{Austenite Formation}

DICTRA results (see Figures 11a and 14a) as well as TEM-EDS analysis (see Figure 9) indicate that at the peak temperature after ultrafast heating, chemical heterogeneity in $\mathrm{C}$ exists in austenite. The partitioning of substitutional atoms, especially $\mathrm{Cr}$, is considered to significantly affect the austenite formation.

Figure 16 shows the simulation results from the ferrite to austenite transformation in conjunction with time. The graphs show that the completion of $\alpha \rightarrow \gamma$ transformation is delayed next to $\mathrm{M}_{7} \mathrm{C}_{3}$ carbide on fine and coarse carbides (see Figure 16b,d). This fact suggests that the strong $\mathrm{Cr}$ enrichment retards the $C$ diffusion, leading to austenite areas depleted in $C$. In case of fine cementite, the austenite formation occurs rapidly, hence the enrichment in $C$. In case of coarse cementite, the austenite formation is substantially delayed (see Figure 16a,c). Furthermore, the existence of undissolved carbides during ultrafast heating act as nucleation points for austenite, while preventing austenite grain growth, hence the refined PAGBs.
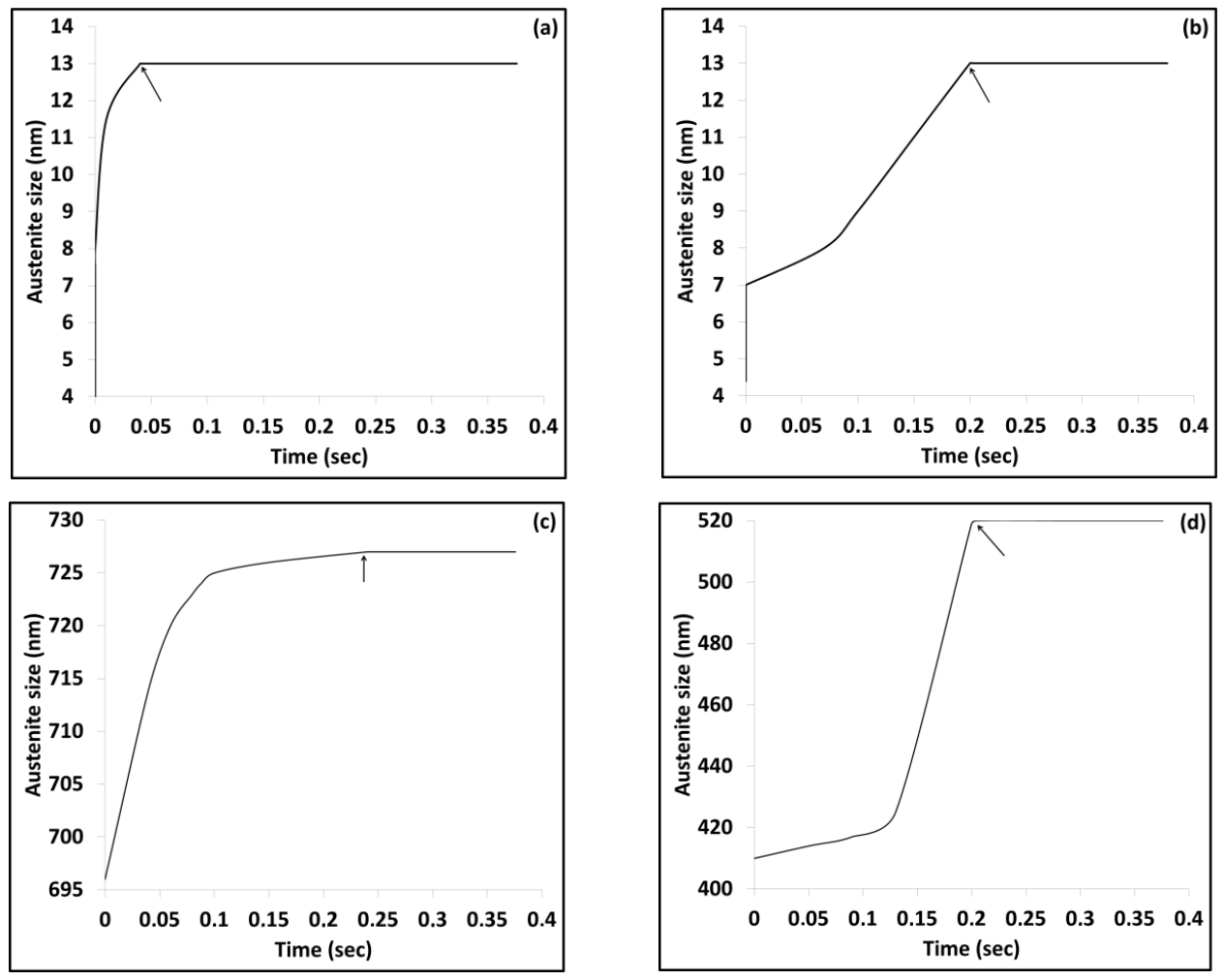

Figure 16. Graphs showing the completion of $\alpha \rightarrow \gamma$ transformation for (a) fine cementite; (b) fine $\mathrm{M}_{7} \mathrm{C}_{3}$ carbide; (c) coarse cementite; $(\mathbf{d})$ coarse $\mathrm{M}_{7} \mathrm{C}_{3}$ carbide. The arrow in each case indicates the $\alpha$ to $\gamma$ transformation. 


\subsection{Phase Transformations during Quenching}

The phenomena that take place during ultrafast heating (UFH) can play a significant role in the onset of phase transformations at the quenching stage. At peak temperature, various austenite grains are present with significant chemical heterogeneity in $C$ and a maximum grain size estimated by EBSD at $10 \mu \mathrm{m}$. The formation of martensite in relatively coarser austenite grains $(\sim 10 \mu \mathrm{m})$ will be favored, since coarser austenite grain size is correlated to high $\mathrm{M}_{\mathrm{s}}$ temperature. The presence of carbon gradients and partitioning of substitutional elements can explain the presence of mixed martensite and bainite microstructures [30]. Generally, the formation of bainitic ferrite is accompanied by carbon diffusion in the austenite matrix, while carbide precipitation enhances the kinetics of bainite formation. During bainite formation, when bainitic ferrite forms, C diffuses into the remaining austenite or the precipitated carbides. When $\mathrm{C}$ diffuses into austenite, the overall kinetics are retarded, but when $\mathrm{C}$ diffuses in carbides, the kinetics for bainite formation are accelerated. With the presence of substitutional element partitioning ( $\mathrm{Cr}, \mathrm{Mn}, \mathrm{Mo}$ ), carbides are stabilized. This means that $\mathrm{C}$ diffusion is impeded in carbides. Thus, partial diffusion takes place in austenite and bainite formation is retarded. The gradual enrichment of $C$ in austenite shifts to lower values of the onset temperature for martensite transformation. Hence, the martensite laths might form at the remaining austenite during quenching. Finally, in austenite areas with $C$ content above $0.7 \mathrm{wt} . \% \mathrm{C}$, the martensite finish temperature $\left(\mathrm{M}_{\mathrm{f}}\right)$ is shifted below room temperature and consequently during quenching, substantial amounts of retained austenite could be found in the microstructure if the $C$ content of the austenite is well above $1 \mathrm{wt}$.\%. Thus, in this case, martensite formation is less likely to occur. Small fractions of retained austenite might lead to increased ductility after the UFHT. However, we could not clearly identify significant amount of retained austenite in the examined UFHT microstructures. In case of large-scale chemical heterogeneity, the described processes will proceed in a similar way.

\section{Conclusion}

An ultrafast heat treatment was applied to CrMo steel, resulting in a refined microstructure consisting of mixed martensite and bainitic ferrite laths and various carbides $\left(\mathrm{M}_{7} \mathrm{C}_{3}\right.$ and cementite) in different nano-sizes ( $5 \mathrm{~nm}$ to $200 \mathrm{~nm}$ ); some of them were from undissolved cementite. The carbide dissolution and austenite formation has been studied and discussed in order to understand the factors that contribute to mixed bainitic/martensitic microstructure. The simulation study indicates that during rapid heating, although time for diffusion is extremely limited, short-range diffusion exists and partial dissolution of carbides is observed, even on fine carbides. Therefore, the carbides found in the final microstructure after the application of an UFHT are actually partly dissolved or undissolved carbides that were originally formed in the initial microstructure. The presence of undissolved carbides also prevents austenite grain growth, resulting in fine austenite grains at the peak temperature (the austenitization temperature with duration of maximum $2 \mathrm{~s}$ ). The dissolution rate of carbides depends on the segregation of substitutional elements ( $\mathrm{r}, \mathrm{Mn}, \mathrm{Mo}$ ). Enrichment in alloying elements, especially in $\mathrm{Cr}$, has been observed at nearby carbide interfaces. The degree of the alloying element segregation, especially $\mathrm{Cr}$, is considered to create solute drag phenomena in carbide/austenite interfaces, thus delaying carbide dissolution. Subsequently, the segregation of substitutional atoms retarded the austenite formation and resulted in carbon-depleted austenite, ensuring chemical heterogeneity at the peak temperature. Finally, the $\mathrm{C}$ chemical heterogeneity along with the segregation of substitutional atoms was showed to have a strong influence on phase transformations during quenching and together with the fine austenite grain boundary sizes explains the set of a mixed martensite/bainitic ferrite microstructure with nano-sized carbides. 
Author Contributions: Conceptualization: S.P.; Methodology: S.P. \& M.B.; Software: M. B.; Validation: M.B. and S.P. \& R.H.P.; Formal Analysis: S.P.; Investigations: S.P., M.B.; Resources: M.B.; Data Curation: M.B.; Writing-Original Draft Preparation: S.P., M.B.; Writing-Review \& Editing: S.P. \& R.H.P.; Visualization: M.B. \& R.H.P.; Supervision: S.P.; Project Administration: S.P.

Funding: This research received no external funding.

Acknowledgments: The authors express their gratitude to the Hellenic Research Centre for Metals-ELKEME S.A. and Thermocalc for support to this research. We thank Petros Tsakiridis from the National Technical University of Athens for his support with Transmission Electron Microscopy. We also thank Athanasios Vazdirvanidis from ELKEME S.A. for his support with EBSD measurements. Many thanks to M. Klinger for the support in our first attempt to use his software CrysTBox diffractGUI 2.19. Furthermore, we thank Constantinos Goulas and Nico Geerlofs from the Materials Science and Engineering Department at the Delft University of Technology for their contribution to the dilatometric experiments. Sincere thanks to Jilt Sietsma for his support with dilatometry. Finally, we thank Felipe M. Castro Cerda and Constantinos Goulas for the discussions on a previous version of this manuscript.

Conflicts of Interest: The authors declare no conflict of interest.

\section{References}

1. Roberts, G.A.; Mehl, R.F. The mechanism and the rate of formation of austenite from ferrite-cementite aggregates. TRANS A.S.M. 1943, 31, 613-650.

2. Kong, L.N.; Liu, Y.H.; Liu, J.A.; Song, Y.L.; Li, S.S.; Zhang, R.H.; Li, T.J.; Liang, Y. The influence of chromium on the pearlite-austenite transformation kinetics of the Fe-Cr-C ternary steels. J. Alloys Compd. 2015, 648, 494-499. [CrossRef]

3. Speich, G.; Szirmae, A.; Richards, M. Formation of austenite from ferrite and ferrite-carbide aggregates. Trans. Metall. Soc. AIME 1969, 245, 1063-1074.

4. Judd, R.R.; Paxton, H.W. Kinetics of austenite formation from a spheroidized ferrite-carbide aggregate. Trans. AIME 1968, 242, 206-215.

5. Hillert, M.; Nilsson, K.; Torndahl, L.-E. Effect of alloying elements on the formation of austenite and dissolution of cementite. J. Iron Steel Inst. 1971, 209, 49-66.

6. Liu, Z.K.; Agren, J. Morphology of cementite decomposition in an Fe-Cr-C alloy. Metal. Trans. A 1991, 22, 1753-1759. [CrossRef]

7. Liu, Z.K.; Hoglund, L.; Jonsson, B.; Agren, J. An experimental and theoretical study of cementite dissolution in a Fe-Cr-C Alloy. Metal. Trans. A 1991, 22, 1745-1752. [CrossRef]

8. Schemmann, L.; Zaefferer, S.; Raabe, D.; Friedel, F.; Mattissen, D. Alloying effects on microstructure formation of dual phase steels. Acta Mater. 2015, 95, 386-398. [CrossRef]

9. Raabe, D.; Herbig, M.; Sandlöbes, S.; Li, Y.; Tytko, D.; Kuzmina, M.; Ponge, D.; Choi, P.-P. Grain boundary segregation engineering in metallic alloys: A pathway to the design of interfaces. Curr. Opin. Solid State Mater. Sci. 2014, 18, 253-261. [CrossRef]

10. Goune, M.; Maugis, P.; Drillet, J. A criterion for the change from fast to slow regime of cementite dissolution in Fe-C-Mn Steels. J. Mater. Sci. Technol. 2012, 28, 728-736. [CrossRef]

11. Lolla, T. Understanding Microstructure Evolution in Rapid Thermal Processing of AISI 8620 Steel. Master's Thesis, The Ohio State University, Columbus, OH, USA, 2009.

12. Cola, G. Properties of bainite nucleated by water quenching in $80 \mathrm{~ms}$. In International Symposium on Steel Science, 1st; Furuhara, T., Tsuzaki, K., Eds.; Iron and Steel Institute of Japan: Tokyo, Japan, 2007; pp. 187-190.

13. Lolla, T.; Alexandrov, B.; Babu, S.; Cola, G. Towards understanding the microstructure development during flash heating and cooling of steels. Presented at the International Conference on processing and manufacturing of advanced materials-THERMEC' 09, Berlin, Germany, 25-29 August 2009.

14. Lolla, T.; Cola, G.; Narayanan, B.; Alexandrov, B.; Babu, S. Development of rapid heating and cooling (flash processing) process to produce advanced high strength steel microstructures. Mater. Sci. Technol. 2011, 27, 863-875. [CrossRef]

15. Holzweissig, M.J.; Lackmann, J.; Konrad, S.; Schaper, M.; Niendorf, T. Influence of short austenitization treatments on the mechanical properties of low-alloyed steels for hot forming applications. Metall. Mat. Trans. A 2015, 46A, 3199-3207. [CrossRef]

16. Goulas, K. Developing Novel Heat treatments for Automotive Spring Steels: Phase Transformations, Microstructure and Performance. Doctoral Thesis, Delft University of Technology, Delft, Netherlands, 2018. 
17. Kaluba, W.J.; Taillard, R.; Foct, J. The bainitic mechanism of austenite formation during rapid heating. Acta Mater. 1998, 46, 5917-5927. [CrossRef]

18. Cerda, F.M.C.; Goulas, C.; Sabirov, I.; Papaefthymiou, S.; Monsalve, A.; Petrov, R.H. Microstructure, texture and mechanical properties in a low carbon steel after ultrafast heating. Mater. Sci. Eng. A 2016, 672, 108-120. [CrossRef]

19. Cerda, F.M.C.; Sabirov, I.; Goulas, C.; Sietsma, J.; Monsalve, A.; Petrov, R.H. Austenite formation in $0.2 \%$ C and $0.45 \%$ C steels under conventional and ultrafast heating. Mater. Des. 2017, 116, 448-460. [CrossRef]

20. Papaefthymiou, S.; Goulas, C.; Cerda, F.M.C.; Geerlofs, N.; Petrov, R.H. The effect of heating rate on the microstructure of a soft-annealed medium carbon steel. Steel Res. Int. 2017, 87, 1-9. [CrossRef]

21. DeKnijf, D.; Puype, A.; Föjer, C.; Petrov, R.H. The influence of ultra-fast annealing prior to quenching and partitioning on the microstructure and mechanical properties. Mater. Sci. Eng. A 2015, 627, 182-190. [CrossRef]

22. Cerda, F.M.C.; Kestens, L.A.I.; Monsalve, A.; Petrov, R.H. The effect of ultrafast heating in cold-rolled low carbon steel: Recrystallization and texture evolution. Metals 2016, 6, 288. [CrossRef]

23. Valdes-Tabernero, M.A.; Vercruysse, F.; Sabirov, I.; Petrov, R.H.; Monclus, M.A.; Molina-Aldareguia, J.M. Effect of ultrafast heating on the properties of the microconstituents in a low-carbon steel. Metall. Mat. Trans. A 2018, 49, 3145-3150. [CrossRef]

24. Andersson, J.; Helander, T.; Höglund, L.; Shi, P.; Sundman, B. Thermo-Calc and DICTRA, computational tools for materials science. Calphad 2002, 26, 273-312. [CrossRef]

25. Klinger, M. CrysTBox-Crystallographic Toolbox; Institute of Physics of the Czech Academy of Sciences: Prague, Czech, 2015.

26. Zakerinia, H.; Kermanpur, A.; Najafizadeh, A. Color metallography; A suitable method for characterization of martensite and bainite in multiphase steels. Int. J. ISSI 2009, 6, 14-18.

27. Lee, S.J.; Lee, Y.K. Effect of austenite grain size on martensitic transformation of a low alloy steel. Mater. Sci. Forum. 2005, 475, 3169-3172. [CrossRef]

28. Karthikeyan, T.; Dash, M.; Saroja, S.; Vijayalakshmi, M. Estimation of Martensite Feature Size in a Low-Carbon alloy Steel by Microtexture Analysis of Boundaries. Micron 2015, 68, 77-90. [CrossRef] [PubMed]

29. Calcagnotto, M.; Ponge, D.; Raabe, D. On the effect of manganese on grain size stability and hardenability in ultrafine grained ferrite/martensite dual-phase steels. Metall. Mat. Trans. A 2012, 43, 37-46. [CrossRef]

30. Goulas, C.; Mecozzi, M.; Sietzma, J. Bainite formation in medium-carbon low-silicon spring steels accounting for chemical segregation. Metall. Mat. Trans. A 2016, 47, 3077-3087. [CrossRef] 